\title{
Ultrahard Carbon Nanocomposite Films
}

\section{RECEIVED FFR 242000}

M. P. Siegal, D. R. Tallant, P. N. Provencio, D. L. Overmyer and R. L. Sirłs 8 T / Sandia National Laboratories, Albuquerque, NM 87185-1421

\author{
L. J. Martinez-Miranda \\ University of Maryland, Department of Materials and Nuclear Engineering \\ College Park, MD 20742
}

\begin{abstract}
Modest thermal annealing to $600^{\circ} \mathrm{C}$ of diamondlike amorphous-carbon (a-C) films grown at room temperature results in the formation of carbon nanocomposites with hardness similar to diamond. These nanocomposite films consist of nm-sized regions of high density a-C embedded in an a-C matrix with a reduced density of $5-10 \%$. We report on the evolution of density and bonding topologies as a function of annealing temperature. Despite a decrease in density, film hardness actually increases $\sim 15 \%$ due to the development of the nanocomposite structure.
\end{abstract}




\section{DISCLAIMER}

This report was prepared as an account of work sponsored by an agency of the United States Government. Neither the United States Government nor any agency thereof, nor any of their employees, make any warranty, express or implied, or assumes any legal liability or responsibility for the accuracy, completeness, or usefulness of any information, apparatus, product, or process disclosed, or represents that its use would not infringe privately owned rights. Reference herein to any specific commercial product, process, or service by trade name, trademark, manufacturer, or otherwise does not necessarily constitute or imply its endorsement, recommendation, or favoring by the United States Government or any agency thereof. The views and opinions of authors expressed herein do not necessarily state or reflect those of the United States Government or any agency thereof. 


\section{DISCLAIMER}

Portions of this document may be illegible in electronic image products. Images are produced from the best available original document. 
Hydrogen-free diamondlike amorphous-carbon (a-C) films consist of a mixture of 3-fold ( $\mathrm{sp}^{2}$-like) and 4-fold ( $\mathrm{sp}^{3}$-like) coordinated atoms. Interest in a-C films is due to its roomtemperature growth (1-3), high-temperature thermal stability (4) and diamondlike tribological properties (5-7). A significant drawback is the as-grown high residual compressive stresses of these films (8). Stresses on the order of several GPa limit the usefulness of a-C, causing delamination of films with thickness $100-200 \mathrm{~nm}$. However, it has been shown that modest thermal annealing to $600{ }^{\circ} \mathrm{C}$ dramatically reduces the as-grown residual stress, enabling the ability to grow a-C films several microns thick (9). The tribological properties of such thick, stress-free a-C films are similar to those of diamond, with hardness near $88 \mathrm{GPa}(10)$. Such stress-reduction is leading to the development of new a-C applications, such as stiff membranes for flexural plate wave sensors and even as structural materials for microelectromechanical systems fabrication (11).

We report on the evolution of bonding structures within a-C films as a result of thermal annealing. We find that the annealing process not only reduces stress, but also rearranges carboncarbon bonding resulting in a nanocomposite material composed purely of a-C. We grow a-C films onto $\mathrm{Si}(100)$ substrates at room-temperature using pulsed-laser deposition (PLD), as described elsewhere (8). Other energetic growth methods, such as filtered cathodic vacuum arc and mass-selected ion beam deposition, may also be used $(1,3)$. Briefly, highly-focussed $248 \mathrm{~nm}$ excimer pulsed-laser radiation $(\mathrm{KrF})$ ablates a rotating pyrolytic graphite target with energy density $=45 \mathrm{~J} / \mathrm{cm}^{2}$, generating a highly energetic (tens of $\mathrm{eV}$ ) carbon species which deposit onto a rotating substrate. The base pressure of the PLD vacuum chamber is less than $10^{-7}$ torr and rises to nearly $10^{-6}$ torr during deposition. We use a commercial rapid thermal processing system for postdeposition annealing to temperatures ranging from 200 to $600{ }^{\circ} \mathrm{C}$ in a pure argon atmosphere in a fused silica chamber with external heating lamps. 
Figure 1(a) is a cross-sectional, high-resolution transmission electron microscopy (HRTEM) image of a $32.5 \mathrm{~nm}$ thick a-C film grown onto Si. Film thickness was kept low due to the typical 5 - $7 \mathrm{GPa}$ residual stresses that causes thick films to literally crumble during foil formation for HRTEM analysis. The contrast variation within the film image is due solely to changes in carbon density. In general, every a-C film has a distinguishable layer of low density near both the substrate and surface regions, and a region of higher density in the middle, or bulk portion, of a film. Depending upon growth energy, this bulk region can have a density gradient that decreases, remains constant, or increases with distance from the substrate interface (12). The decreasing density gradient seen here is typical of films grown using PLD (13). Nevertheless, note the homogeneity of density parallel to the substrate, and the smooth evolution of density in the growth direction.

We processed by RTA a second sample cut from the same as-grown film shown in fig. 1(a) at $600{ }^{\circ} \mathrm{C}$ in $\mathrm{Ar}$ for 30 minutes. This results in an elimination of measurable residual film stress and enables the growth of thicker films via multiple deposition and anneal cycles (10). Figure 1(b) is an HRTEM image of this residual stress-free film. Annealed films show dramatic changes in density variation compared with the as-grown films. The dark spots, on the order of $3-5 \mathrm{~nm}$ in diameter, are $5-10 \%$ more dense than the lighter contrast surrounding regions. These comparative measurements are made parallel to the substrate surface to exclude the effects of the density gradient perpendicular to the surface found in the as-grown films.

Upon observing the development of this nanocomposite structure, we became curious about the nature of the nearly diamondlike hardness reported for such annealed films. Amorphous carbon films contain considerable fractions of 3-fold coordinated carbon. Furthermore, the stressreduction annealing process further increases the 3 -fold coordinated carbon content at the expense of the 4-fold coordinated fraction. Perhaps the annealing process used for stress reduction is also 
responsible for the reported $88 \mathrm{GPa}$ hardness values. To test this hypothesis, we grew a $110 \mathrm{~nm}$ thick a-C film on a two-inch $\mathrm{Si}(100)$ wafer, cleaved it in half, and annealed one half by RTA at 600 ${ }^{\circ} \mathrm{C}$ in $\mathrm{Ar}$ for 30 minutes. Hardness on both the as-grown and annealed samples was measured using nanoindentation accomplished by pushing a small diamond indenter, with an effective tip radius $<50 \mathrm{~nm}$, into a sample and then withdrawing it, recording the force required as a function of position. Since these relatively thin a-C films are on a significantly softer $\mathrm{Si}$ substrate, determination of the true hardness values requires finite-element modeling (14). However, since our two samples are of identical thickness on the same substrate, differences in the measurements will approximate a direct ratio of the actual hardness values. We find that the hardness of these a-C films increases nearly $15 \%$ with an anneal at $600{ }^{\circ} \mathrm{C}$. We believe that the development of an a-C nanocomposite, as shown in figure $1 \mathrm{~B}$, is responsible for these increased values. The remainder of this letter studies the nature of this unique, pure carbon, totally amorphous nanocomposite structure.

$\mathrm{X}$-ray reflectivity (XRR) infers film density from the critical angle of total internal reflection. Using $\mathrm{Cu} \mathrm{K}_{\alpha 1}$ radiation from a $12 \mathrm{~kW}$ rotating anode source with a resolution of $0.001 \AA^{-1}$, we collected XRR spectra from nominally $95 \mathrm{~nm}$ thick a-C films cut from the same growth substrate and annealed for two hours at temperatures ranging from $200-600^{\circ} \mathrm{C}$. Figure 2 shows the XRR inferred densities of the films as a function of annealing temperature. Density values $\sim 3 \mathrm{~g} / \mathrm{cm}^{3}$ are typical for a-C films of this thickness grown using similar PLD conditions (15). Film density decreases appreciably with annealing above $200{ }^{\circ} \mathrm{C}$, dropping to $\sim 2.8 \mathrm{~g} / \mathrm{cm}^{3}$ by $600{ }^{\circ} \mathrm{C}$. This $\sim 7$ $\%$ drop in overall density is in good agreement with the ratio determined from HRTEM image contrast. Decreases in a-C density may result in either increases in the ratio of 3-fold to 4-fold coordinated $\mathrm{C}$ atoms or a rearrangement of bonding configurations, and is consistent with the general decrease in residual film stress and electrical resistivity reported elsewhere (16). 
We investigated the annealing-induced changes in bonding topologies of a-C using Raman spectroscopy. Exciting Raman scatter with the $514.5 \mathrm{~nm}$ wavelength (green light) of an argon ion laser preferentially samples 3-fold coordinated carbon atoms due to resonant enhancement through low-lying electronic orbitals. Figure 3(a) shows the as-grown and $600^{\circ} \mathrm{C}$ annealed Raman spectra for the same films measured by XRR. We normalize the spectra to the carbon peak height. A change in surface roughness with annealing temperature, detected by XRR (17), contributes to differences in Raman intensities. The spectra for the films annealed from $200-500{ }^{\circ} \mathrm{C}$ fit monotonically between these two spectra and are not shown for clarity. The feature occurring between 925 and $1025 \mathrm{~cm}^{-1}$ is a second-order phonon band from the silicon substrate. Note that the intensity of the $\mathrm{Si}$ band decreases with increasing temperature, indicating that a-C becomes less transparent upon annealing. In fact, the decrease in the ratio of the Si:C Raman band intensities shown in fig. 3(b) represents a monotonic decrease in optical transparency that is consistent with an increase in the 3-fold coordinated carbon fraction of the films; i.e. a-C becomes less diamondlike with thermal annealing. This is not surprising given that graphitic bonding is thermodynamically more stable than diamondlike bonding.

The broad Raman band between 1050 and $1850 \mathrm{~cm}^{-1}$ and centered near $1570 \mathrm{~cm}^{-1}$ is due to resonantly-enhanced vibrational modes of 3 -fold coordinated carbon. We further analyze the subtle changes in these carbon spectra by considering the physical characteristics of thermodynamically stable solid-state $\pi$-bonded structures. The topographical distribution of 3-fold coordinated carbon atoms in highly diamondlike a-C should include small, relatively isolated graphene clusters. Conjugated chain-like structures may also exist, perhaps even dominate the real structure, but they cannot account for the observed Raman spectra, most likely due to resonantenhancement issues (15). While 6-membered ring topologies are the most stable, rings of other sizes are possible in solid-state materials. For example, fullerenes include 5- and 7-membered carbon rings to impart curvature. We deconvolute the $\mathrm{C}$ bands using vibrational frequencies 
calculated from idealized 5-, 6-, and 7-membered $\pi$-bonded carbon ring clusters (18) in a manner described elsewhere (15). While idealized ring structures are unlikely to occur in a-C films with high local strains, vibrational shifts due to distortions tend to broaden the range of frequencies rather than to shift the average vibrational frequency for a given ring structure. Since 6-membered carbon rings are the most thermodynamically stable $\pi$-bonded structure, we assume that small clusters of such rings are present and exhibit Raman-active breathing (A-type symmetry class) and stretching (E-type symmetry class) vibrational modes. The highly strained environment within these a-C films will force curvature in these clusters, resulting in the evolution of both 5- and 7 membered rings. However, since 5- and 7-membered rings lack inversion symmetry, the A modes dominate their Raman scatter. Hence, four vibrational bands, three with A-type symmetry (from 5-, 6-, and 7-membered rings) and one with E-type symmetry (from 6-membered rings), were used to simulate the Raman spectra.

Figure 4 shows the fractional contribution of each vibrational frequency to the entire 3-fold coordinated carbon portion of the Raman spectra as a function of annealing temperature. Since asgrown films have the smallest population of $\pi$-bonded carbon, we expect to find the smallest and most isolated clusters, leading to a preponderance of 6-membered rings. This distribution remains relatively constant for annealing temperatures up to $300{ }^{\circ} \mathrm{C}$. However, recall that both the density and transparency measurements imply a steady in bonding topologies. In particular, the densities plotted in figure 2 show measurable changes by $300^{\circ} \mathrm{C}$. Above this temperature, the fraction of 5 membered rings begins to increase dramatically. This is consistent with an increase in the $\pi$ bonded fraction which leads to the development of larger ring clusters. Despite the reduction occurring in residual film stress, the local bonding environments continue to exist within considerable strain fields. Therefore, for the $\pi$-bonded ring clusters to grow in size without forming layered graphite-like structures, they must develop curvature to maintain a high degree of atomic packing. This transformation of $\sigma$-bonded atoms into $\pi$-bonded atoms is driven by 
thermodynamic considerations, hence, 5-membered ring structures, which are more stable than 7membered rings, increase in population (16). This does not mean that the 6-membered ring population is decreasing, only that newly formed $\pi$-bonded atoms are grouping into 5 -membered rings.

In summary, we find that annealing smooth and homogeneous diamondlike a-C films to temperatures near $600{ }^{\circ} \mathrm{C}$ transforms them into nanocomposites of pure amorphous carbon. This new structure consists of highly dense a-C clusters with diameters of $3-5 \mathrm{~nm}$ in a matrix of $5-$ $10 \%$ less dense a-C. Average film density reduces monotonically with annealing temperature, consistent with the decrease in optical transparency. These reductions result from the conversion of 4-fold coordinated carbon atoms into thermodynamically more stable, 3-fold coordinated atoms. Nanoindentation measurements of the final nanocomposite structure, known to have hardness near $88 \mathrm{GPa}$, find it to be $\sim 15 \%$ harder than as-grown films.

The authors thank J. C. Barbour and J. A. Knapp for valuable discussion and J. P. Sullivan for providing some a-C films. This work was supported in part by Sandia National Laboratories, US DOE under contract No. DE-ACO4-94AL85000 and from the NSF under grant DMR9313047.

Sandia is a multiprogram laboratory operated by Sandia Corporation, a Lockheed Martin Company, for the United States Department of Energy under contract DE-AC04-94AL85000. 


\section{References:}

1. S. Kasi, H. Kang, and J. W. Rabalais, Phys. Rev. Lett. 59, 75 (1987).

2. S. S. Wagal, E. M. Juengerman, and C. B. Collins, Appl. Phys. Lett. 53, 187 (1988).

3. P. J. Martin, S. W. Filipczuk, R. P. Netterfield, J. S. Field, D. F. Whitnall, and D. R. McKenzie, J. Mater. Sci. Lett. 7, 410 (1988).

4. T. A. Friedmann, K. F. McCarty, J. C. Barbour, M. P. Siegal, and D. C. Dibble, Appl. Phys. Lett. 68, 1643 (1996).

5. C. B. Collins, F. Davanloo, D. R. Jander, T. J. Lee, H. Park, and J. H. You, J. Appl. Phys. 69, 7862 (1991).

6. G. M. Pharr, D. L. Callahan, S. D. McAdams, T. Y. Tsui, S. Anders, J. W. Ager III, I. G. Brown, C. S. Bhatia, S. R. P. Silva, and J. Robertson, Appl. Phys. Lett. 68, 779 (1996).

7. A. A. Voevodin, M. S. Donley, J. S. Zabinsky, and J. E. Bultman, Surf. Sci. Coat. Technol. 77, 534 (1995).

8. M. P. Siegal, T. A. Friedmann, S. R. Kurtz, D. R. Tallant, R. L. Simpson, F. Dominguez, and K. F. McCarty, Mater. Res. Soc. Proc. 349, 507 (1994).

9. J. P. Sullivan, T. A. Friedmann, R. G. Dunn, E. B. Stechel, P. A. Schultz, M. P. Siegal, and N. Missert, Mater. Res. Soc. Proc. 498, 97 (1998).

10. T. A. Friedmann, J. P. Sullivan, J. A. Knapp, D. R. Tallant, D. M. Follstaedt, D. L. Medlin, and P. B. Mirkarimi, Appl. Phys. Lett. 71, 3820 (1997).

11. J. P. Sullivan, paper presented at the 1998 Fall Materials Research Society Meeting, Boston, MA 2 December 1998.

12. M. P. Siegal, P. N. Provencio, D. R. Tallant, R. L. Simpson, B. Kleinsorge, and W.I. Milne, unpublished material.

13. M. P. Siegal, J. C. Barbour, P. N. Provencio, D. R. Tallant, T. A. Friedmann, Appl. Phys. Lett. 73, 759 (1998). 
14. J. A. Knapp, D. M. Follstaedt, S. M. Myers, J. C. Barbour, and T. A. Friedmann, J. Appl. Phys. 85, 1460 (1999).

15. M. P. Siegal, D. R. Tallant, L. J. Martinez-Miranda, J. C. Barbour, R. L. Simpson, and D. L. Overmyer, Phys. Rev B, (in press).

16. J. P. Sullivan, T. A. Friedmann, and A. G. Baca, J. Electron. Mater. 26, 1021 (1997).

17. L. J. Martinez-Miranda, M. P. Siegal, P. N. Provencio, and J. P. Sullivan, (unpublished).

18. T. E. Doyle and J. R. Dennison, Phys. Rev. B, 51, 196 (1995). 


\section{Figure Captions}

1. Cross-sectional HRTEM images of (a) as-grown and, (b) $600{ }^{\circ} \mathrm{C}$ annealed a-C films from the same growth sample. The second image was enhanced by Fourier filtering for clarity. All of the features can also be observed in the unfiltered image.

2. Film density inferred by XRR vs. annealing temperature.

3. (a) Raman spectra for the as-grown and $600{ }^{\circ} \mathrm{C}$ annealed a-C samples. (b) Si/C Raman band intensity ratio (an indication of optical transparency) vs. annealing temperature.

4. Contribution to the carbon Raman band from the vibrations of 5-, 6-, and 7-membered rings vs. annealing temperature. 

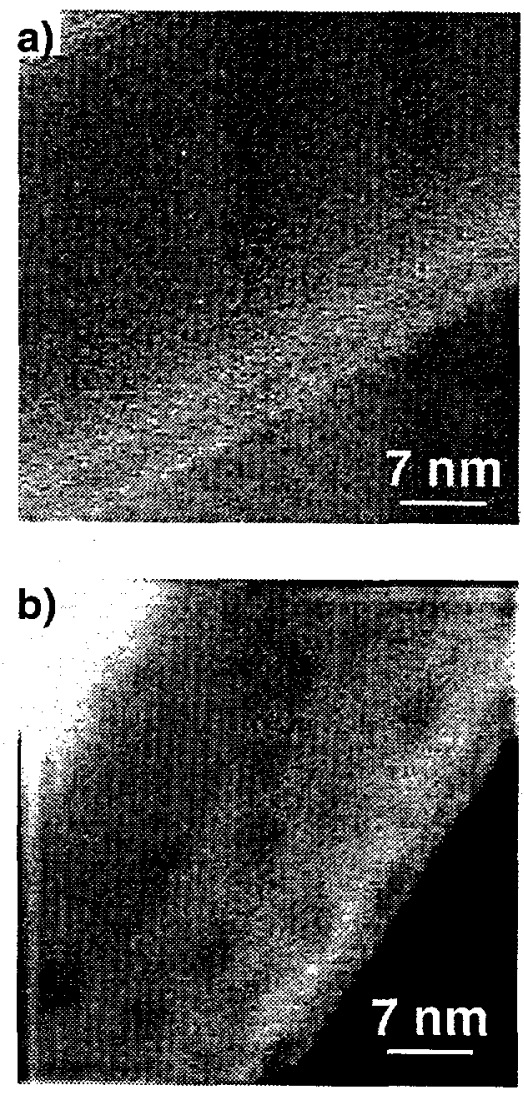

Fig. 1 (of 4)

M. P. Siegal

Appl. Phys. Lett. 


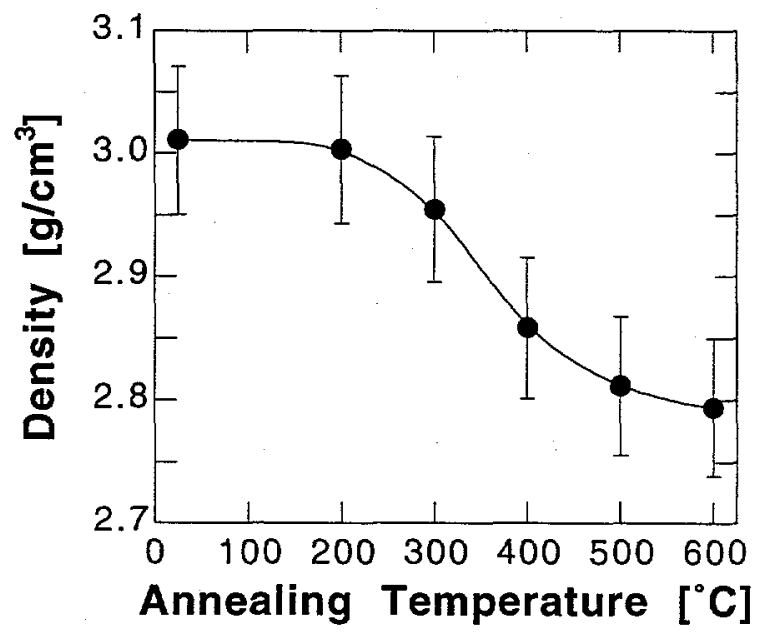

Fig. $2(0+4)$

M.P. Siegal

Appl. Phys. Lett. 

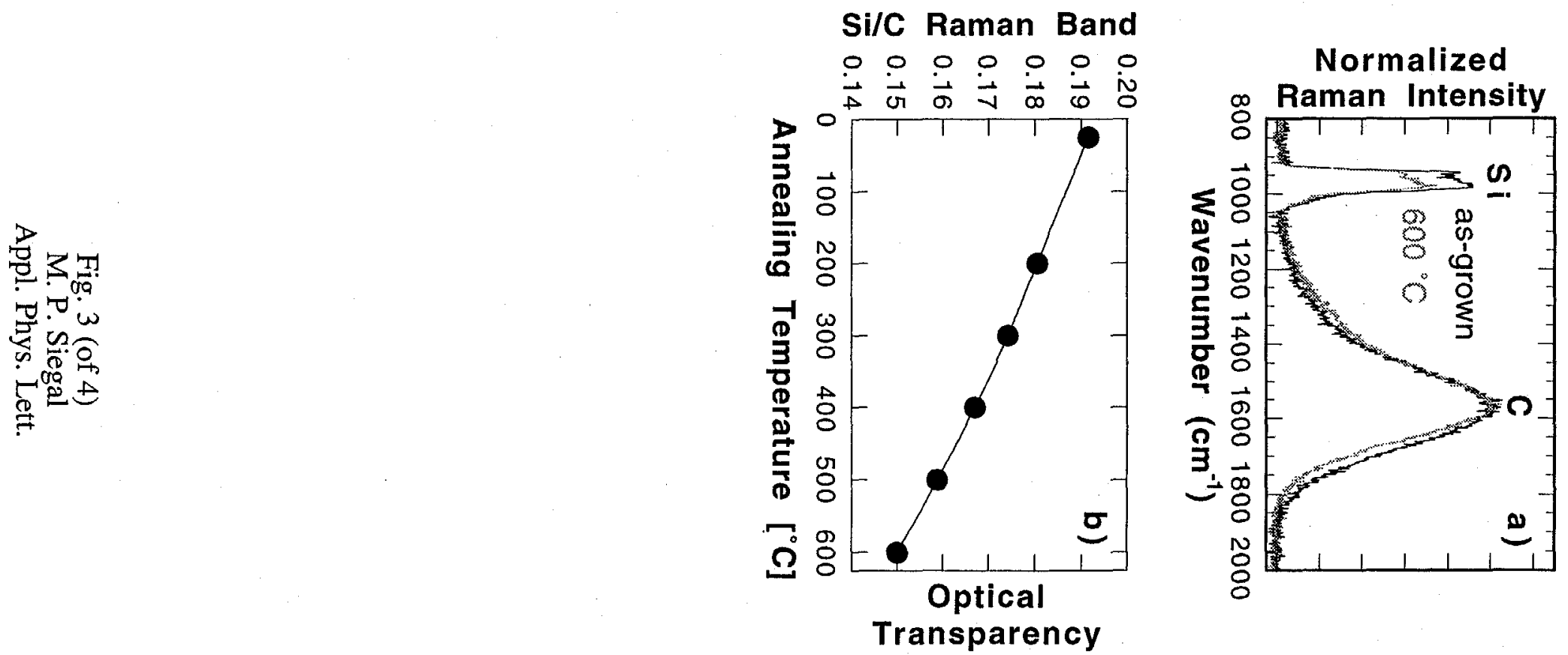


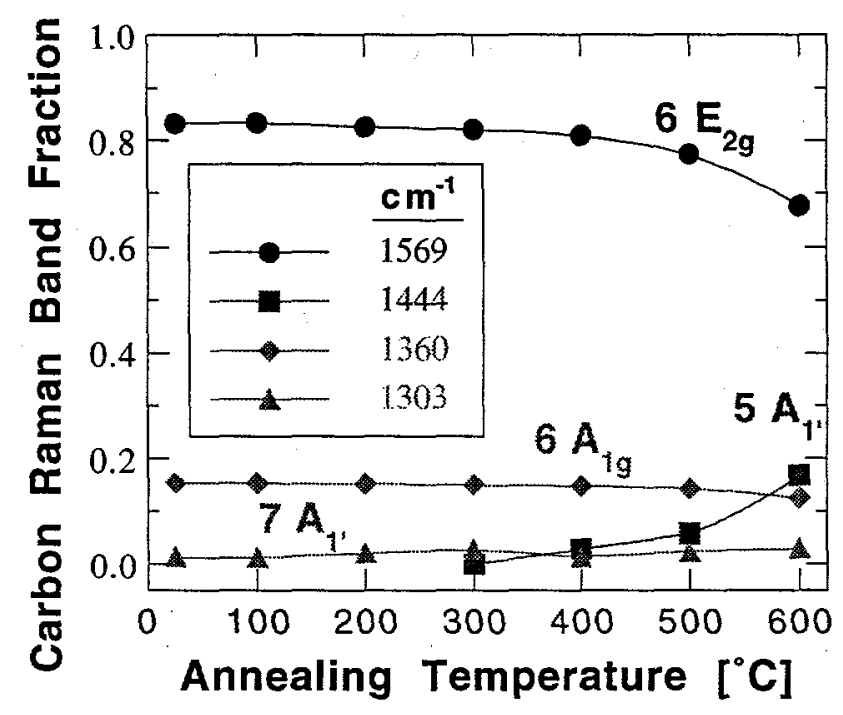

Fig $4(\operatorname{ot} 4)$

M. P. Siegal

App. Phys. Lett. 